\title{
Sensitivity Analysis of a Conceptual, Lumped Model Using VARS- TOOL Applied to Western Ghats Catchments of India
}

\author{
KRISHNA S, S. DEB BARMA* and MAHESHA AMAI \\ Department of Applied Mechanics and Hydraulics, National Institute of Technology \\ Karnataka, Surathkal, Mangalore - 575025, India; *Corresponding author, Surajit Deb \\ Barma, Email: surajitdb@gmail.com.
}

This manuscript has been submitted as a non-peer reviewed preprint to EarthArXiv prior to submitting to the peer reviewed Journal of Earth System Science (JESS) of Springer Nature.

$28^{\text {th }}$ January 2020. 


\title{
Sensitivity Analysis of a Conceptual, Lumped Model Using VARS-TOOL Applied to Western Ghats Catchments of India
}

\author{
KRISHNA S, S. DEB BARMA* and MAHESHA AMAI
}

Department of Applied Mechanics and Hydraulics, National Institute of Technology Karnataka, Surathkal, Mangalore - 575025, India; *Corresponding author, Surajit Deb Barma, Email: surajitdb@gmail.com;

\begin{abstract}
The present work considers the application of Variogram Analysis of Response Surfaces Toolbox (VARS-TOOL) to identify the sensitive parameters of a rainfall-runoff model in the Netravati river basin of Karnataka, India using the global sensitivity analysis method. The statistical bootstrapping method is used to obtain the confidence intervals around each of the sensitivity indices. The VARS-TOOL generates results based on the different approaches considering the desired sampling technique and the rankings and reliability estimates of the rankings of the different parameters can be obtained. The sensitive parameters from most influential to least influential parameters are grouped and represented in the form of a dendrogram. The precipitation multiplier, fraction of soil entering fast reservoir and slow reservoir coefficients were found to be most influential parameters for the basin. The air temperature threshold for melting/freezing and base melt factor was least influential. The results of the present study can prove to be helpful in further understanding of the application of VARS-TOOL and can be used for further development of the toolbox for sensitivity analysis.
\end{abstract}

Keywords: HBV model, Netravati basin, PLHS, Sensitivity Analysis, VARS-TOOL, Western Ghats

\section{Introduction}

Earth system models play a major role in decision making within a confidence interval, by offering predictive capacity and support for scenario assessment. Different hydrological models provide distinct perspectives of modelling and approximate several 
governing processes expressed in terms of parameters. By understanding the processes and their heterogeneity, these models improve in their complexities. This has led to computationally intensive models with various parameters which have an effect on the models. Hence, the effects of these parameters are uncertain and it must be understood and characterised. Therefore, it is necessary to consider these uncertainties in model. The sensitivity analysis involves determining the contribution of each input of the model to the uncertainties in the output. A systematic classification of sensitivity analysis methods used in environmental modelling and their application is reported elsewhere (Gan et al. 2014; Pianosi et al. 2016). The analysis of variance and Sobol's method were found to be superior to the regional sensitivity analysis and parameter estimation software (Tang et al. 2007). The local sensitivity was the basis for early sensitivity analysis studies, which is focused on the effects of uncertain inputs around a point, which is found to be potentially false and also incomplete (Saltelli and Annoni 2010). It has led to a high standard known as global sensitivity analysis (GSA) (Saltelli et al. 2008; Sheikholeslami et al. 2018) which is increasingly used in environmental modelling (Pianosi et al. 2015). The GSA methods estimate the influence of all the inputs or their aggregated effect on the change in output.

The VARS-TOOL is a multi-approach toolbox which is based on the theory of Variogram Analysis of Response Surfaces (VARS) (Razavi and Gupta 2019). It uses the directional variogram and co-variograms to define sensitivity which results in less computational cost. Considering the challenges involved in global sensitivity analysis methods like more computationally intensive models or cost effective and the conflicting assessments of sensitive parameters when using different approaches, VARS was developed. The VARS has a variogram-based paradigm for GSA which bridges the normally used gradient-based approach and the variance-based approach. The VARS could uniquely characterise the perturbation-scale dependency and generate sensitivity measures applicable to all the perturbation scales (Haghnegahdar and Razavi 2017).

The VARS yields an original set of sensitivity metrics called IVARS (Integrated Variogram Across a Range of Scales). These metrics will show the rate of change in the model response within a scope, which is known as perturbation scale in the parameter space. The VARS also produces the Sobol (variance-based) total-order effect and the Morris (derivative-based) elementary effects. In the present work, the STAR (space-time autoregressive model)-VARS was utilised which is statistically robust as well as highly 
efficient and offers stable outcomes when compared to other approaches (Razavi and Gupta 2016b).

The Hydrologiska Byrans Vattenbalansavdelning (HBV) model was introduced in 1972 (Bergström and Forsman 1973) by the Swedish Meteorological and Hydrological Institute (SMHI). The HBV model is a conceptual hydrological model mainly used for runoff simulation and hydrological forecasting which was proved to be reasonably accurate (Lindstrom et al. 1997). It was originally developed to assist hydropower operations by providing the hydrological forecasts. In data scarce regions data from regional climate models may be used as input in HBV models for discharge simulations which proved good in terms of both robustness and uncertainty ranges (Akhtar et al. 2009). The HBV model in a semi-humid catchment in Mississippi, USA was applied by Abebe et al. (2010). The analysis of sensitivity of each of the parameters was carried out by calibrating the model using MOSCEM (Multi-Objective Shuffled Complex Evolution) algorithm and was found that, identifiability and sensitivity of parameters were quite different for the HBV hydrologic model with the objective functions of NS, RMSE and BIAS. The HBV-Light model applied to Narayani river, Nepal was able to simulate the peak flows correctly except a few sharp peaks but the low flows were underestimated (Bhattarai et al. 2018) which was proved to be the other way for another basin in Nepal (Normand et al. 2010).

In the present study, the VARS-TOOL has been applied to a rainfall-runoff model (HBV) in the Netravati basin. The main objective of the work is to understand the application of the newly developed toolbox to the basin and to identify the most sensitive parameters. It is necessary to establish a strategic sensitivity analysis technique to estimate parameters and to comprehend the behaviour of the hydrological model to more representative parameter changes and identify the dependencies of these parameters in the model solution. Therefore, the evaluation of a distributed, conceptual model like HBV is necessary to determine the uncertainty and sensitivity of the rainfall-runoff model using different GSA methods. The HBV is mainly used in the regions where snowfall is involved but its application in other regions is to be explored and no studies have been reported with HBV model application in India.

\section{Study Area}

\subsection{Study Area Characteristics}


The river Netravati is one of the west flowing rivers originating from the Western Ghats of India falling in the range $12^{\circ} \mathrm{N}-13^{\circ} 11^{\prime} \mathrm{N}$ and $74^{\circ} 54^{\prime} \mathrm{E}-75^{\circ} 47^{\prime} \mathrm{E}$ (figure 1a).

Figure 1a. Study Area (Netravathi basin)

The Netravati basin extends over $3411 \mathrm{~km}$ square area, and has a total length of $103 \mathrm{~km}$. The Kumaradhara river is its major tributary which joins at Uppinangadi. The other tributaries are Shishila hole, Kerehole, Yettinahole, Hongadhallad hole and Kadumane hole. The average annual rainfall in the basin varies from $2970 \mathrm{~mm}$ to $5585 \mathrm{~mm}$. The elevation range is $0 \mathrm{~m}$ (at Mangalore) to 1200 meters (at origin) above the mean sea level (figure 1b).

Figure 1b. The digital elevation map of Netravathi basin

The maximum temperature ranges from $26.4^{\circ} \mathrm{C}$ to $35^{\circ} \mathrm{C}$ and the minimum temperature ranges from $22^{\circ} \mathrm{C}$ to $27.2^{\circ} \mathrm{C}$. Broadly speaking, the relative humidity is very high attaining levels of saturation during the months of monsoon. The geology of the city is characterized by hard laterite in hilly tracts and sandy soil near seashore. The geology map of Dakshina Kannada district of scale 1: 500000 is digitized and Netravati basin is extracted (figure 2).

Figure 2. The geology map of Netravathi basin

$70 \%$ consists of gneiss complex rock which is a common and widely distributed type of metamorphic rock. The geomorphology map of Dakshina Kannada district in 1:50000 scale is collected from Geological Survey of India, Bengaluru. The soil map was obtained from NBSS \& LUP (National Bureau of Soil Survey and Land Use Planning) for the year 2003. Based on the soil types the catchment is classified into 18 categories. Different soils have different hydraulic conductivity, soil erodibility factor, infiltration capacity etc., influencing the water balance and sediment yield from the watershed. The soil map of Netravati is shown in figure 3.

Figure 3. Soil Map of Netravathi basin

The LU/LC map was downloaded from Decadal LU/LC. This data collection offers land use and land cover grouping products at $100 \mathrm{~m}$ resolution for India at decadal periods for 1985, 1995 and 2005. A myriad of data sets from different sensors, viz., Enhanced Thematic Mapper (ETM), Landsat 4 and 5 Thematic Mapper (TM), Multispectral (MSS), Resourcesat, Linear Imaging Self Scanning Sensor-I or III (LISS-I, LISS-III) including from ground truth 
surveys and visual interpretation were obtained. The LU/LC map of Netravati is shown in figure 4 . The study region predominantly has forest area.

Figure 4. The LU/LC map of Netravathi basin

The Netravati river is gauged at Bantwal gauging station by the Central Water Commission (CWC). In addition, other gauging sites upstream at Uppinangadi and Surve (figure 5) are (collected by the State Department) are selected to compare the results of sensitivity.

Figure 5. Drainage map of Netravathi river with gauging stations

The Sarve basin, which is the basin of Gowri Hole, is located at $75^{\circ} 17^{\prime} \mathrm{E} 12^{\circ} 43^{\prime} \mathrm{N}$ and has an area of $126 \mathrm{sq} . \mathrm{km}$. The Uppinangadi basin is located at the confluence of rivers Kumardhara and Netravati $\left(75^{\circ} 15^{\prime}\right.$ E $\left.12^{\circ} 55^{\prime} \mathrm{N}\right)$ and covers an area of $1095 \mathrm{sq} . \mathrm{km}$. The historical record of precipitation, streamflow and temperature of the main basin Netravati are represented in figure 6. The long term monthly average (1971-2007) stream flow at Bantwal is shown in figure 7.

Figure 6. Historical record of precipitation, streamflow and temperature for Netravathi basin

Figure 7. Long term monthly average streamflow at Bantwal station (1971-2007)

\subsection{Data Used}

The current study uses daily meteorological data for the period 1971-2007 which is procured from the India Meteorological Department (IMD). The IMD gridded rainfall data $\left(0.25^{0} \times 0.25^{0}\right)$ and $1^{0} \times 1^{0}$ temperature data were collected for the period 1971-2011. The $1^{\circ} \mathrm{x}$ $1^{\circ}$ temperature was converted to 0.25 degree using MATLAB and the values of rainfall and temperature were extracted. The long term average precipitation, temperature and potential evapotranspiration were estimated for the required time period for each of the study area from the daily data. The rainfall, streamflow and temperature records were available for 25 years (1978-2002) for Bantwal and Uppinangadi stations and for 8 years (1996-2003) for Sarve station. The Thiessen polygon method was used to get the average value of rainfall over the basin with 14 grid points.

\section{Methods}


The entire problem is run in MATLAB environment, including the HBV model. There are 12 parameters considered in this model the details of which are available elsewhere (Razavi et al. 2019). Of this, the first 11 model parameters are related to hydrologic processes, whereas the $12^{\text {th }}$ parameter is considered to explain for error in precipitation. Out of the above, the main parameters used in the HBV model are discussed here. The bifurcation of precipitation into rain and snow was revealed to notably influence the simulation of water and energy balance (Wen et al. 2013). Therefore, the air threshold temperature (TT) in ${ }^{\circ} \mathrm{C}$ for freezing/melting and separation of rain and snow was considered. The temperature deviation correction in $1 /{ }^{\circ} \mathrm{C}$ of potential evapotranspiration. A positive departure indicates that, the measured temperature is warmer than the baseline temperature, averaged over the data, while a negative departure indicates the measured temperature is cooler than the baseline. The limit for potential evapotranspiration (LP) is a multiplier to the field capacity (FC), i.e, a soil moisture value beyond which evapotranspiration reaches its permissible value. $\beta$ is a dimensionless shape parameter which is an exponent for the soil release equation which controls the contribution to the response function or the increase in soil moisture storage from rainfall. The fraction of soil moisture entering fast reservoir (FRAC) and $\mathrm{K} 1$ and $\mathrm{K} 2$ are the fast and slow reservoir coefficients which determine the proportion of storage released in a day. $\alpha$ is a shape parameter that is used for fast reservoir equation. UBAS is the base of the unit hydrograph used for watershed routing in day and PM is a precipitation multiplier to address any uncertainties in precipitation. For accounting of input uncertainty, spatiallydistributed hydrological modelling requires precipitation multiplier approaches. The lower and upper bounds of the parameters are listed in table 1.

Table 1. Parameters used for study in HBV-SASK model

The VARS makes use of anisotropic variogram and model response co-variogram features as the grounds for a thorough characterisation of global sensitivity to produce directional variograms connected with each of the model variables. The directional variogram shows the variance of the response which is due to the perturbation of that factor across a complete range of perturbation scales. The integration of the directional variograms are done for computing the sensitivity indices in VARS, which gives a broad set of metrics for global sensitivity, known as "Integrated Variograms Across a Range of Scales" or IVARS. The IVARS50 index, also termed as the "total-variogram effect" , sums the variogram across the complete array of perturbation scales and is the most wide-ranging variogram-based index for global sensitivity. The STAR-VARS is a special execution of VARS which is merged within 
the VARS-TOOL. This execution employs a method of star-based sampling (called STAR) (Razavi and Gupta 2016a). The IVARS along with the gradient- and variance-based indices are calculated for global sensitivity using VARS-TOOL, fully in one run that uses the same sample point (Razavi et al. 2019).

The sensitivity metrics generated by VARS are stored in text files (VARS_out_XX.txt, where $\mathrm{XX}$ is used to represent the number of STARS used in the analysis). For an array of step sizes, the outcomes comprise the directional variograms, IVARS indices (Integrated Variogram Across a Range of Scales), VARS-based appraisals of variance-based Total-Order Effects (Sobol's approach), and VARS-based estimates of different types of derivative-based Elementary Effects (Morris' approach). The inconsistency of evolution in model response is dependent on perturbation measure in a certain direction (distance in the related direction) in the factor space, which is represented by the directional variogram. The IVARS sums the directional variogram over a scale array from zero to $\mathrm{H}_{\mathrm{i}}$ in the $\mathrm{i}^{\text {th }}$ direction and hence, offers a summary index for global sensitivity for any given interval of measure. The IVARS $\mathrm{xx}_{\mathrm{x}}$ refers to the integrated variogram with a $\mathrm{Hi}$ value of $\mathrm{XX} \%(0 . \mathrm{XX})$ of the factor range. The application of IVARS10, IVARS30, and IVARS50 are suggested (calculated for 0.1, 0.3, and 0.5 of the factor range, respectively). The degree of inconsistency across an interval of measure in the factor space is expressed as:

$$
\gamma\left(h_{i}\right)=0.5 . V\left(y\left(x_{1}, \ldots, x_{i}+h_{i}, \ldots, x_{n}\right)-y\left(, x_{1}, ., x_{i}, . . x_{n}\right)\right)
$$

in an $n$-dimensional factor space, $x=$ any location in space $=\left\{\mathrm{x}_{1}, \mathrm{x}_{2}, . . \mathrm{x}_{\mathrm{i}}, . . \mathrm{x}_{\mathrm{n}}\right\} ; y=$ the model response $=\mathrm{f}\left(\mathrm{x}_{1}, \mathrm{x}_{2}, \ldots \mathrm{x}_{\mathrm{n}}\right) ; h_{i}=$ size of change in the $i^{\text {th }}$ direction $(\mathrm{i}=1,2, \ldots \mathrm{n})$ and $\mathrm{V}(\mathrm{)})=$ variance function.

A dendrogram is obtained after factor grouping for the HBV model. The performance metrics generated on the basis of sensitivity of the parameters on the observed and simulated flows over the recorded data. On the basis of their influence the parameters are arranged, starting from most dominant (to the left-hand) and least dominant (to the right-hand).

The Root Mean Squared Error (RMSE), NSE (Nash- Sutcliffe Efficiency) and Mean Absolute Error were chosen to determine the sensitivity metrics for Sarve and Uppinangadi basins. For the Netravati basin, only RMSE metric was generated. For monthly stream flow simulation, Moriasi et al. (2015) proposed NSE $>0.5$ and $\mathrm{R}^{2}>0.6$ to be satisfactory. The VARS was run in online mode for the Netravati basin. The model was run for a single output, 
ie, stream flow. The PLHS was the sampling strategy chosen to run the model. The total number of stars considered for STAR-VARS run is 100. All the sensitivity indices are stored in VARS_out_XX.txt. Here, XX is from 10 to 100 as 100 stars were taken for the model run. Figure 8 shows the methodology of the present work.

Figure 8. Methodology of the present simulation

\section{Results and Discussion}

\subsection{VARS Results for Netravati basin}

The ranking of parameters on the basis of IVARS50 and the reliability estimates of the rankings during each STAR run are shown in figures 9 and 10 respectively.

Figure 9. Evolution and convergence of sensitivity indices after GSA execution for Nethravati basin

Figure 10. Detailed GSA results - directional variogram across the range of perturbation scales for Netravati basin

The VARS has the advantage that the results during each STAR run can be seen in the form of graphs. In figure 9, the final result including the rankings and reliability estimates after 100 STAR runs can be observed. In figure 10, the directional variogram and the sensitivity metric vs input factors plot showing confidence intervals for the sensitive parameters are shown. These plots are helpful to the user to monitor how a change in sample size affects the estimates of factor sensitivities and rankings (as more model evaluations become available). The Sobol' sensitivity analysis could be successfully applied for factor fixing and factor prioritization with respect to the input parameters of a SWAT model (Nossent et al. 2011). From the graphs and outputs containing RMSE sensitivity metrics generated by running the program, it is evident that, the PM (Precipitation multiplier to reduce error in precipitation), K2 (Slow reservoir coefficient) and FRAC are the most sensitive indices affecting the output. Figure 11, shows the dendrogram for factor grouping created for Netravati basin parameters represented by the HBV model. This assemblage is created on the sensitivity of RMSE metric on the modelled and recorded stream flows over the measured record to the 12 parameters. The parameters are arranged from most dominant (to the left-hand), i.e., K2, PM and FRAC to the least dominant (to the right-hand), i.e., TT and $\mathrm{C}$. The ideal grouping by elbow method is linked to coloured sets. The factors are clustered into a unit of clusters which can 
be entered by the user or the VARS-TOOL will recommend an ideal unit of clusters, based on maximising the differences between the groups by using "elbow method".

Figure 11. Dendrogram for factor grouping

The first three sensitive parameter rankings (K2, PM and FRAC) are the same after both VARS-TO and IVARS executions. These parameters are grouped as the most influential parameters. The VARS-TO groups the parameters into 3 groups, while, IVARS groups them into 4 groups based on their influence on the simulated value. Table 2 lists the factor rankings based on VARS-TO and IVARS for the Netravati basin.

Table 2. Factor Rankings based on VARS-TO and IVARS for RMSE metric (Netravati basin)

For the Netravati basin, PM and FRAC were the most sensitive parameters, of which PM is the most sensitive. This may be due to uncertainties in the precipitation input provided. Table 3 lists the reliability estimates of the factor rankings.

Table 3. Reliability estimates of factor rankings based on VARS-TO and IVARS for RMSE metric (Netravati Basin)

Table 4. Factor grouping by elbow method for RMSE metric ( Netravati basin)

For VARS-TO, the reliability estimates are varying from $0.9-1$, which is highly reliable. In IVARS50, the reliability shows a range of 0.6 to 1 , which is also fairly reliable. Table 4 shows the grouping of factors based on their influence on the simulated results (in this case, streamflow). The factor assemblage is created on the sensitivity of RMSE performance index on the modelled and measured stream flows over the chronological period to the 12 model factors.

\subsection{VARS Results for Sarve and Uppingadi basins}

The VARS was also run for Sarve and Uppinangadi sub-basins of Netravati river. As Netravati is a basin of large area with varying topography and climate, the rankings and sensitivity of the various parameters may be different in different regions. In order to compare the results, two smaller sub-basins were selected at different locations and results 
were analysed on the basis of RMSE, MAE and NSE metrics. For both stations, MAE, RMSE and NSE metrics were generated and related graphs are plotted. Table 5 to table 10 show the factor rankings, reliability estimates of the rankings and the factor groupings based on the RMSE metrics for Serve and Uppinangadi stations.

Table 5. Factor Rankings based on VARS-TO and IVARS for RMSE metric (Sarve basin)

Table 6. Reliability estimates of factor rankings based on VARS-TO and IVARS for RMSE metric (Sarve Basin)

Table 7. Factor Grouping by elbow method (RMSE metric - Sarve basin)

From the analysis of VARS for Sarve and Uppinangadi basins, it is clear that K2, PM and FRAC are the most influencing cofficients. The same coefficients were obtained as the sensitive parameters for Netravati basin as well. While factor grouping, in Sarve basin, FC also comes under the most influential parameter group. The parameters are similar to that of the Netravati basin sensitive parameters except that, there is slight variation in the rankings. The reliability estimates of the rankings vary from 0.55 to 1 for VARS-TO method and 0.58 to 1 for IVARS50.

Table 8. Factor Rankings based on VARS-TO and IVARS for RMSE metric (Uppinangadi basin)

Table 9. Reliability estimates of factor rankings based on VARS-TO and IVARS for RMSE metric (Uppinangadi Basin)

Table 10. Factor grouping by elbow method (RMSE metric - Uppinangadi basin)

Often, in most of the hydrological models, these parameters are not generally considered. Therefore, application of the HBV model considering the sensitive parameters can improve and help in effective hydrological modelling of the area.

\section{Conclusions}

There is a need for the sensitivity and error investigation to be an essential portion of any model progress, expectation, and decision-making process. This gives an intuition into various issues like uncertainty apportionment, diagnostic testing, planning and management, and policy prioritization. Computational difficulties and lack of interpretability and transparency hamper some of the best practices in modelling. The VARS-TOOL is designed such that, complicated, multi-dimensional and computationally expensive models can be simplified using the computationally efficient toolbox.

From the study, it is evident that, the application of VARS-TOOL is very efficient for the sensitive parameter rankings and also for the reliability estimation. 
- In the case of Netravati, using RMSE metric, PM (Precipitation multiplier to address uncertainties in rainfall), FRAC (fraction of soil release entering fast reservoir) and K2 (Slow reservoir coefficient) are the most sensitive indices with ranks 1,2 and 3 respectively.

- The reliability estimates for these three rankings were 1 , ie. $100 \%$ reliability. The estimates ranged from 0.9-1 for VARS-TO and 0.6-1 for IVARS estimates.

- For Sarve basin, MAE, RMSE and NSE metrics were used. With MAE metric, K2 was ranked 1, followed by FRAC and PM. In both the other metrics, it was same as that of Netravati basin.

- For Uppinangadi basin, using MAE, RMSE and NSE metrics, has the same sensitive parameters as Netravati basin.

- The reliability estimates showed a range from 0.6 to 1 for all the metrics generated. It indicates that, the rankings of the parameters are reliable.

- Grouping mechanism in VARS toolbox has grouped these 3 parameters (PM, K2 and FRAC) as group 1 (most influential parameters) and the rest into group 2 and 3 with decreasing sensitivity.

With the help of VARS, clear visualisation and easier interpretation of the results is possible. As reliability estimates of the parameter rankings are also available, it is easier to judge whether the results obtained are completely reliable. The conventional methods like Sobol, Morris approaches can be replaced with VARS, since it gives results with less computational cost. Also, VARS acts as a bridge between the conventional methods. As different methods consider different philosophies, it is necessary to have a method which considers all these different theories.

Some of the limitations of the study are:

- The main parameters in HBV model are snow related parameters. Though it is suggested that HBV can be applied in India, some parameters could not be considered since the study area is not a snow region.

- The time period of input data considered is different for the study areas. If the same time period is taken, a more reliable result may be obtained.

The HBV model can be effectively applied in a snow region in India and VARS can be executed. Also, VARS can be applied to other models in other programming languages other than HBV or MATLAB. 


\section{Acknowledgements}

The authors would like to express their sincere gratitude to the Central Water Commission, Karnataka State Water Resources Development and Management and the India Meteorological Department for providing valuable data for the investigation.

\section{References}

Abebe N A, Ogden F L and Pradhan N R 2010 Sensitivity and uncertainty analysis of the conceptual HBV rainfall-runoff model: Implications for parameter estimation; J. Hydrol., 389 301-310. https://doi.org/10.1016/j.jhydrol.2010.06.007.

Akhtar M, Ahmad N and Booij M J 2009 Use of regional climate model simulations as input for hydrological models for the Hindukush-Karakorum-Himalaya region; Hydrol. Earth Syst. Sci. 13 1075-1089. https://doi.org/10.5194/hess-13-1075-2009.

Bergström S and A Forsman 1973 Development of a conceptual deterministic rainfall-runoff model; Nord. Hydrol. 4 147-170. https://doi.org/10.2166/nh.1973.0012.

Bhattarai S, Zhou Y, Shakya N and Zhao C 2018 Hydrological modelling and climate change impact assessment using HBV light model: A case study of Narayani river basin, Nepal; Nat. Environ. Pollut. Technol. J. 17 691-702.

Gan Y, Duan Q, Wei G, Tong C, Sun Y, Wei C, Ye A, Miao C and Zhenhua D 2014 A comprehensive evaluation of various sensitivity analysis methods: A case study with a hydrological model; Environ. Model. Softw. 51 269-285. https://doi.org/10.1016/j.envsoft.2013.09.031.

Haghnegahdar A and Razavi S 2017 Insights into sensitivity analysis of Earth and environmental systems models: On the impact of parameter perturbation scale; Environ. Model. Softw. 95 115-131. https://doi.org/10.1016/j.envsoft.2017.03.031.

Lindstrom G, Johansson B, Persson M, Gardelin M and Bergstrom S 1997 Development and test of the distributed HBV-96 hydrological model; J. Hydrol. 201 272-288. https://doi.org/10.1016/S0022-1694(97)00041-3.

Moriasi D N, Gitau M W, Pai N and Daggupati P 2015 Hydrologic and water quality models: Performance measures and evaluation criteria; Trans. ASABE 58 1763-1785. http://dx.doi.org/10.13031/trans.58.10715. 
Normand S, M Konz and J. Merz 2010 An application of the HBV model to the Tamor Basin in Eastern Nepal; J. Hydrol. Meteorol. 7 49-58. https://doi.org/10.3126/jhm.v7i1.5616.

Nossent J, Elsen P and Bauwens W 2011 Sobol sensitivity analysis of a complex environmental model; Environ. Model. Softw. 26 1515-1525. https://doi.org/10.1016/j.envsoft.2011.08.010.

Pianosi F, Beven K, Freer J, Hall JW, Rougier J, Stephensone. D B and Wagener T 2016 Sensitivity analysis of environmental models: A systematic review with practical workflow; Environ. Model. Softw. 79 214-232. https://doi.org/10.1016/j.envsoft.2016.02.008.

Pianosi F, Sarrazin F and Wagener T 2015 A MATLAB toolbox for global sensitivity analysis; Environ. Model. Softw. 70 80-85. https://doi.org/10.1016/j.envsoft.2015.04.009.

Razavi S and H V Gupta 2016a A new framework for comprehensive, robust, and efficient global sensitivity analysis: 1. Theory; Water Resour. Res. 52 423-439. https://doi.org/10.1002/2015WR017558.

Razavi S and H V Gupta 2016b A new framework for comprehensive, robust, and efficient global sensitivity analysis: 2. Application; Water Resour. Res. 52 440-455. https://doi.org/10.1002/2015WR017559.

Razavi S, Sheikholeslami R, Hoshin V Gupta and Haghnegahdara A 2019 VARS-TOOL: A toolbox for comprehensive, efficient, and robust sensitivity and uncertainty analysis; Environ. Model. Softw. 112 95-107. https://doi.org/10.1016/j.envsoft.2018.10.005.

Razavi S and Gupta V 2019 A multi-method Generalized Global Sensitivity Matrix approach to accounting for the dynamical nature of earth and environmental systems models; Environ. Model. Softw. 114 1-11. https://doi.org/10.1016/j.envsoft.2018.12.002.

Saltelli A and Annoni P 2010 How to avoid a perfunctory sensitivity analysis. Environ. Model. Softw. 25 1508-1517. https://doi.org/10.1016/i.envsoft.2010.04.012.

Saltelli A, Ratto M, Andres T, Campolongo F, Cariboni J, Gatelli D, Saisana M and Tarantola S 2008 Global Sensitivity Analysis, The Primer John Wiley \& Sons Ltd.

Sheikholeslami S, Razavi S, Gupta H, Becker W and Haghnegahdar A 2018 Global sensitivity analysis for high-dimensional problems: How to objectively group factors and 
measure robustness and convergence while reducing computational cost; Environ. Model. Softw. 111282 - 299. https://doi.org/10.1016/j.envsoft.2018.09.002

Tang Y, Reed P, Wagener T and van Werkhoven K 2007 Comparing sensitivity analysis methods to advance lumped watershed model identification and evaluation; Hydrol. Earth Syst. Sci. 11 793-817. https://doi.org/10.5194/hess-11-793-2007.

Wen L, Nagabhatla N, Lu S and Wang S-Y 2013 Impact of rain snow threshold temperature on snow depth simulation in land surface and regional atmospheric models; Adv. Atmos. Sci. 30 1449-1460. https://doi:10.1007/s00376-012-2192-7. 
Table 1. Parameters used for study in HBV-SASK model

\begin{tabular}{cccc}
\hline No. & Parameter Name & Lower Bound & Upper Bound \\
\hline 1 & TT & -4 & 4 \\
2 & C0 & 0 & 10 \\
3 & ETF & 0 & 1 \\
4 & LP & 0 & 1 \\
5 & FC & 50 & 500 \\
6 & $\beta$ & 1 & 3 \\
7 & FRAC & 0.1 & 0.9 \\
8 & K1 & 0.05 & 1 \\
9 & $\alpha$ & 1 & 3 \\
10 & K2 & 0 & 0.05 \\
11 & UBAS & 1 & 3 \\
12 & PM & 0.5 & 2 \\
\hline
\end{tabular}


Table 2. Factor Rankings based on VARS-TO and IVARS for RMSE metric (Netravati basin)

\begin{tabular}{ccccc}
\hline Factor & $\begin{array}{c}\text { Factor Rankings } \\
\text { based on VARS-TO }\end{array}$ & \multicolumn{3}{c}{ Factor Rankings based on IVARS } \\
\cline { 3 - 5 } & 11 & 11 & $\mathrm{~h}=0.3$ & $\mathrm{~h}=0.5$ \\
\hline TT 0 & 12 & 12 & 11 & 11 \\
ETF & 6 & 6 & 7 & 12 \\
LP & 9 & 9 & 9 & 6 \\
FC & 5 & 7 & 6 & 9 \\
$\beta$ & 10 & 10 & 10 & 5 \\
FRAC & 2 & 2 & 2 & 10 \\
K1 & 8 & 8 & 8 & 2 \\
$\alpha$ & 7 & 4 & 4 & 8 \\
K2 & 3 & 3 & 3 & 7 \\
UBAS & 4 & 5 & 5 & 3 \\
PM & 1 & 1 & 1 & 4 \\
\hline
\end{tabular}


Table 3. Reliability estimates of factor rankings based on VARS-TO and IVARS for RMSE metric (Netravati Basin)

\begin{tabular}{ccccc}
\hline Factor & $\begin{array}{c}\text { Reliability Estimates } \\
\text { of Factor Rankings } \\
\text { based on VARS-TO }\end{array}$ & \multicolumn{3}{c}{$\begin{array}{c}\text { Reliability Estimates of Factor Rankings } \\
\text { based on IVARS }\end{array}$} \\
\cline { 3 - 5 } TT & 1 & $\mathrm{~h}=0.1$ & $\mathrm{~h}=0.3$ & $\mathrm{~h}=0.5$ \\
C0 & 1 & 1 & 1 & 1 \\
ETF & 0.935 & 0.5 & 0.494 & 0.604 \\
LP & 0.986 & 1 & 1 & 1 \\
FC & 0.918 & 0.481 & 0.493 & 0.636 \\
$\beta$ & 1 & 1 & 1 & 1 \\
FRAC & 1 & 1 & 1 & 1 \\
K1 & 0.978 & 0.91 & 1 & 1 \\
$\alpha$ & 0.985 & 0.995 & 0.654 & 0.686 \\
K2 & 1 & 1 & 1 & 1 \\
UBAS & 0.981 & 0.995 & 0.654 & 0.982 \\
PM & 1 & 1 & 1 & 1 \\
\hline
\end{tabular}


Table 4. Factor grouping by elbow method for RMSE metric ( Netravati basin)

\begin{tabular}{ccc}
\hline Factor & $\begin{array}{c}\text { Factor grouping based on } \\
\text { VARS-TO }\end{array}$ & $\begin{array}{c}\text { Factor grouping based on } \\
\text { IVARS }\end{array}$ \\
\hline TT & 2 & 3 \\
C0 & 2 & 3 \\
ETF & 3 & 1 \\
LP & 3 & 3 \\
FC & 3 & 1 \\
$\beta$ & 3 & 3 \\
FRAC & 1 & 2 \\
K1 & 3 & 1 \\
$\alpha$ & 3 & 4 \\
K2 & 1 & 4 \\
UBAS & 3 & 1 \\
PM & 1 & 2 \\
\hline
\end{tabular}

Table 5. Factor Rankings based on VARS-TO and IVARS for RMSE metric (Sarve basin)

\begin{tabular}{|c|c|c|c|c|}
\hline \multirow{2}{*}{ Factor } & Factor Rankings based on & \multicolumn{3}{|c|}{ Factor Rankings based on IVARS } \\
\cline { 2 - 5 } & VARS-TO & $\mathrm{h}=0.1$ & $\mathrm{~h}=0.3$ & $\mathrm{~h}=0.5$ \\
\hline TT & 11 & 11 & 11 & 11 \\
\hline C0 & 12 & 12 & 12 & 12 \\
\hline ETF & 5 & 7 & 7 & 5 \\
\hline LP & 8 & 9 & 8 & 8 \\
\hline FC & 4 & 4 & 4 & 4 \\
\hline$\beta$ & 10 & 10 & 10 & 10 \\
\hline FRAC & 2 & 2 & 2 & 2 \\
\hline K1 & 9 & 8 & 9 & 9 \\
\hline$\alpha$ & 7 & 5 & 6 & 6 \\
\hline K2 & 3 & 3 & 3 & 3 \\
\hline UBAS & 6 & 6 & 7 & 7 \\
\hline PM & 1 & 1 & 1 & 1 \\
\hline
\end{tabular}


Table 6. Reliability estimates of factor rankings based on VARS-TO and IVARS for RMSE metric (Sarve Basin)

\begin{tabular}{|c|c|c|c|c|}
\hline \multirow{2}{*}{ Factor } & $\begin{array}{c}\text { Reliability Estimates of } \\
\text { Factor Rankings based on } \\
\text { VARS-TO }\end{array}$ & \multicolumn{3}{|c|}{$\begin{array}{c}\text { Reliability Estimates of Factor Rankings } \\
\text { based on IVARS }\end{array}$} \\
\cline { 3 - 5 } & 1 & $\mathrm{~h}=0.1$ & $\mathrm{~h}=0.3$ & $\mathrm{~h}=0.5$ \\
\hline TT & 1 & 1 & 1 & 1 \\
\hline C0 & 1 & 0.806 & 0.833 & 0.998 \\
\hline ETF & 0.76 & 0.409 & 0.497 & 0.575 \\
\hline LP & 1 & 1 & 1 & 1 \\
\hline FC & 0.763 & 0.333 & 0.501 & 0.594 \\
\hline$\beta$ & 1 & 0.963 & 0.64 & 0.909 \\
\hline FRAC & 0.927 & 0.11 & 0.907 & 0.963 \\
\hline K1 & 0.547 & 0.91 & 0.606 & 0.509 \\
\hline$\alpha$ & 1 & 1 & 1 & 1 \\
\hline K2 & 0.612 & 0.44 & 0.867 & 0.729 \\
\hline UBAS & 1 & 0.963 & 0.6 & 1 \\
\hline PM & & & & \\
\hline
\end{tabular}

Table 7. Factor Grouping by elbow method (RMSE metric - Sarve basin)

\begin{tabular}{|c|c|c|}
\hline Factor & $\begin{array}{c}\text { Factor grouping based on } \\
\text { VARS-TO }\end{array}$ & $\begin{array}{c}\text { Factor grouping based on } \\
\text { IVARS }\end{array}$ \\
\hline TT & 2 & 2 \\
\hline C0 & 2 & 4 \\
\hline ETF & 1 & 4 \\
\hline LP & 1 & 1 \\
\hline FC & 3 & 2 \\
\hline$\beta$ & 1 & 4 \\
\hline FRAC & 3 & 1 \\
\hline K1 & 1 & 3 \\
\hline$\alpha$ & 1 & 4 \\
\hline K2 & 3 & 3 \\
\hline UBAS & 1 & \\
\hline PM & 3 & 3 \\
\hline
\end{tabular}


Table 8. Factor Rankings based on VARS-TO and IVARS for RMSE metric (Uppinangadi basin)

\begin{tabular}{|c|c|c|c|c|}
\hline \multirow{2}{*}{ Factor } & $\begin{array}{c}\text { Factor Rankings based on } \\
\text { VARS-TO }\end{array}$ & \multicolumn{3}{|c|}{ Factor Rankings based on IVARS } \\
\cline { 2 - 5 } & 11 & $\mathrm{~h}=0.1$ & $\mathrm{~h}=0.3$ & $\mathrm{~h}=0.5$ \\
\hline TT & 12 & 11 & 11 & 11 \\
\hline C0 & 10 & 10 & 12 & 12 \\
\hline ETF & 8 & 8 & 8 & 10 \\
\hline LP & 5 & 6 & 6 & 5 \\
\hline FC & 9 & 9 & 9 & 9 \\
\hline$\beta$ & 2 & 2 & 2 & 2 \\
\hline FRAC & 7 & 7 & 7 & 7 \\
\hline K1 & 4 & 3 & 4 & 4 \\
\hline$\alpha$ & 3 & 4 & 3 & 3 \\
\hline K2 & 6 & 5 & 5 & 6 \\
\hline UBAS & 1 & 1 & 1 & 1 \\
\hline PM & & & & \\
\hline
\end{tabular}

Table 9. Reliability estimates of factor rankings based on VARS-TO and IVARS for RMSE metric (Uppinangadi Basin)

\begin{tabular}{|c|c|c|c|c|}
\hline Factor & $\begin{array}{c}\text { Reliability Estimates of } \\
\text { Factor Rankings based on } \\
\text { VARS-TO }\end{array}$ & \multicolumn{3}{|c|}{$\begin{array}{c}\text { Reliability Estimates of Factor Rankings } \\
\text { based on IVARS }\end{array}$} \\
\cline { 3 - 5 } & 1 & $\mathrm{~h}=0.1$ & $\mathrm{~h}=0.3$ & $\mathrm{~h}=0.5$ \\
\hline TT & 1 & 1 & 1 & 1 \\
\hline C0 & 1 & 1 & 1 & 1 \\
\hline ETF & 0.844 & 0.987 & 0.923 & 0.88 \\
\hline LP & 0.606 & 0.78 & 0.818 & 0.846 \\
\hline FC & 0.955 & 1 & 0.996 & 0.984 \\
\hline$\beta$ & 1 & 1 & 1 & 1 \\
\hline FRAC & 0.811 & 0.777 & 0.904 & 0.858 \\
\hline K1 & 0.607 & 0.563 & 0.973 & 0.917 \\
\hline$\alpha$ & 1 & 0.887 & 0.981 & 1 \\
\hline K2 & 0.864 & 1 & 1 & 1 \\
\hline UBAS & 1 & & & 0.82 \\
\hline PM & & 0.563 & 1 \\
\hline
\end{tabular}


Table 10. Factor grouping by elbow method (RMSE metric - Uppinangadi basin)

\begin{tabular}{|c|c|c|}
\hline Factor & $\begin{array}{c}\text { Factor grouping based on } \\
\text { VARS-TO }\end{array}$ & $\begin{array}{c}\text { Factor grouping based on } \\
\text { IVARS }\end{array}$ \\
\hline TT & 3 & 2 \\
\hline C0 & 3 & 2 \\
\hline ETF & 4 & 5 \\
\hline LP & 4 & 4 \\
\hline FC & 1 & 5 \\
\hline$\beta$ & 4 & 3 \\
\hline FRAC & 2 & 4 \\
\hline K1 & 4 & 1 \\
\hline$\alpha$ & 1 & 1 \\
\hline K2 & 1 & 4 \\
\hline UBAS & 1 & 3 \\
\hline PM & 2 & \\
\hline
\end{tabular}




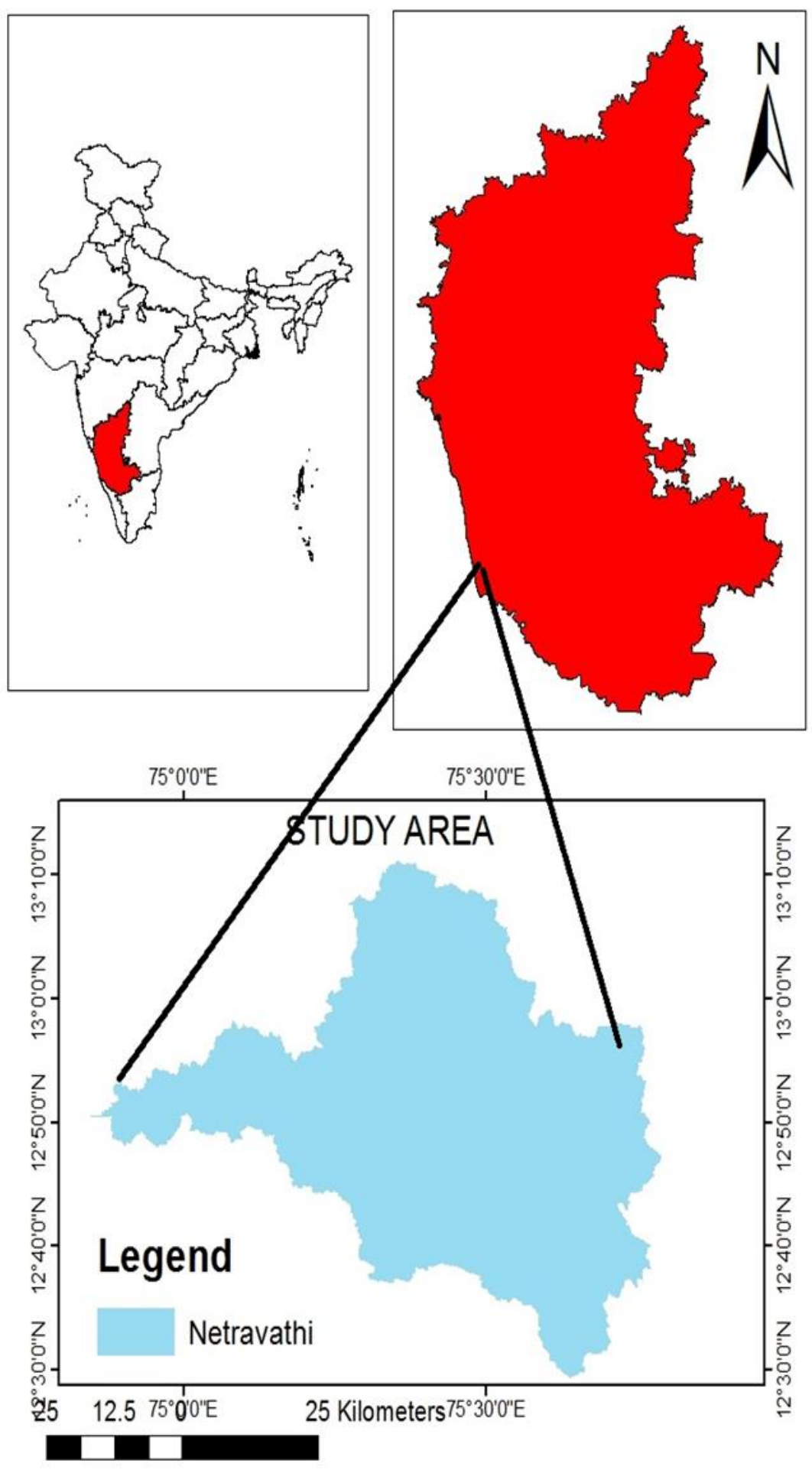

Fig. 1a. The Netravathi river basin, India 


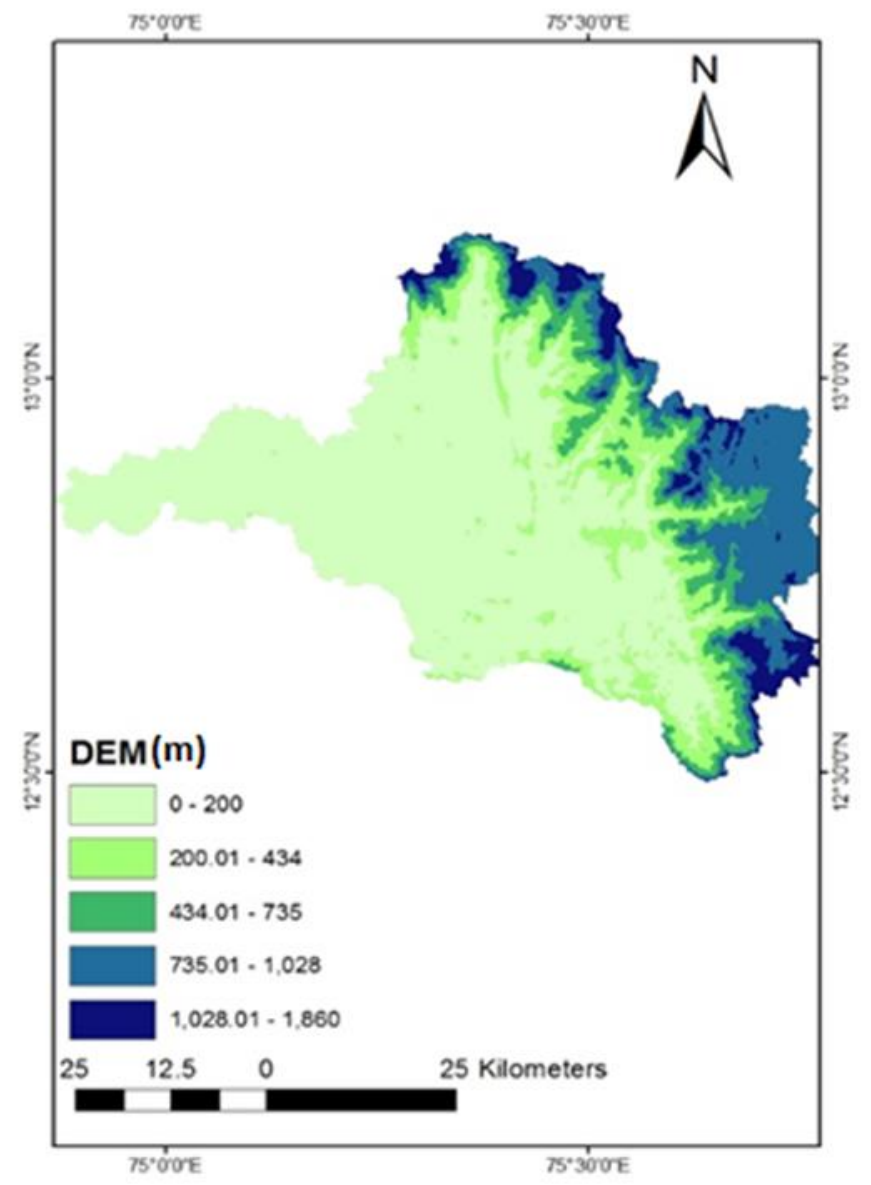

Figure $1 b$. The digital elevation map of Netravathi basin. 


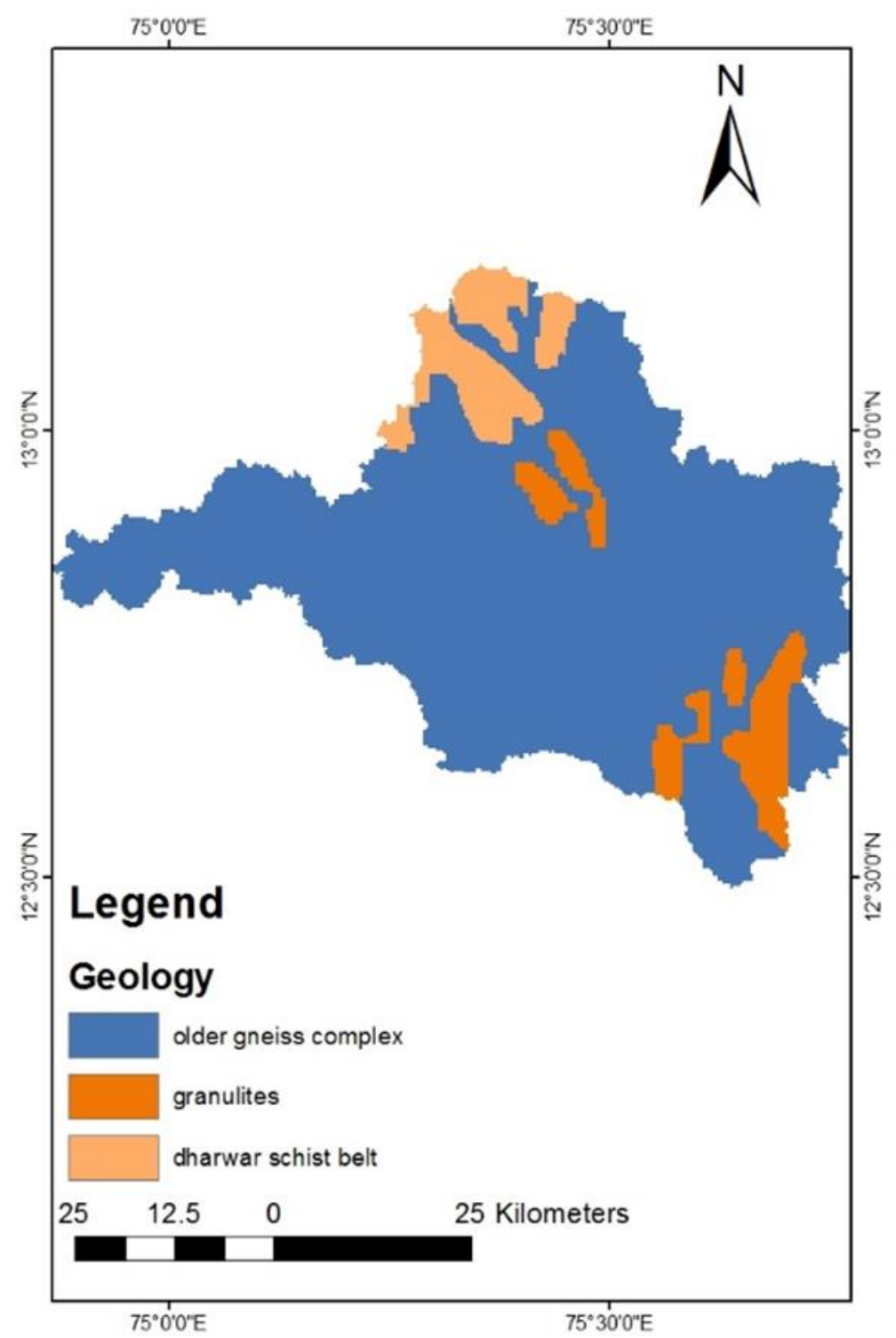

Figure 2. The geology map of Netravathi basin 


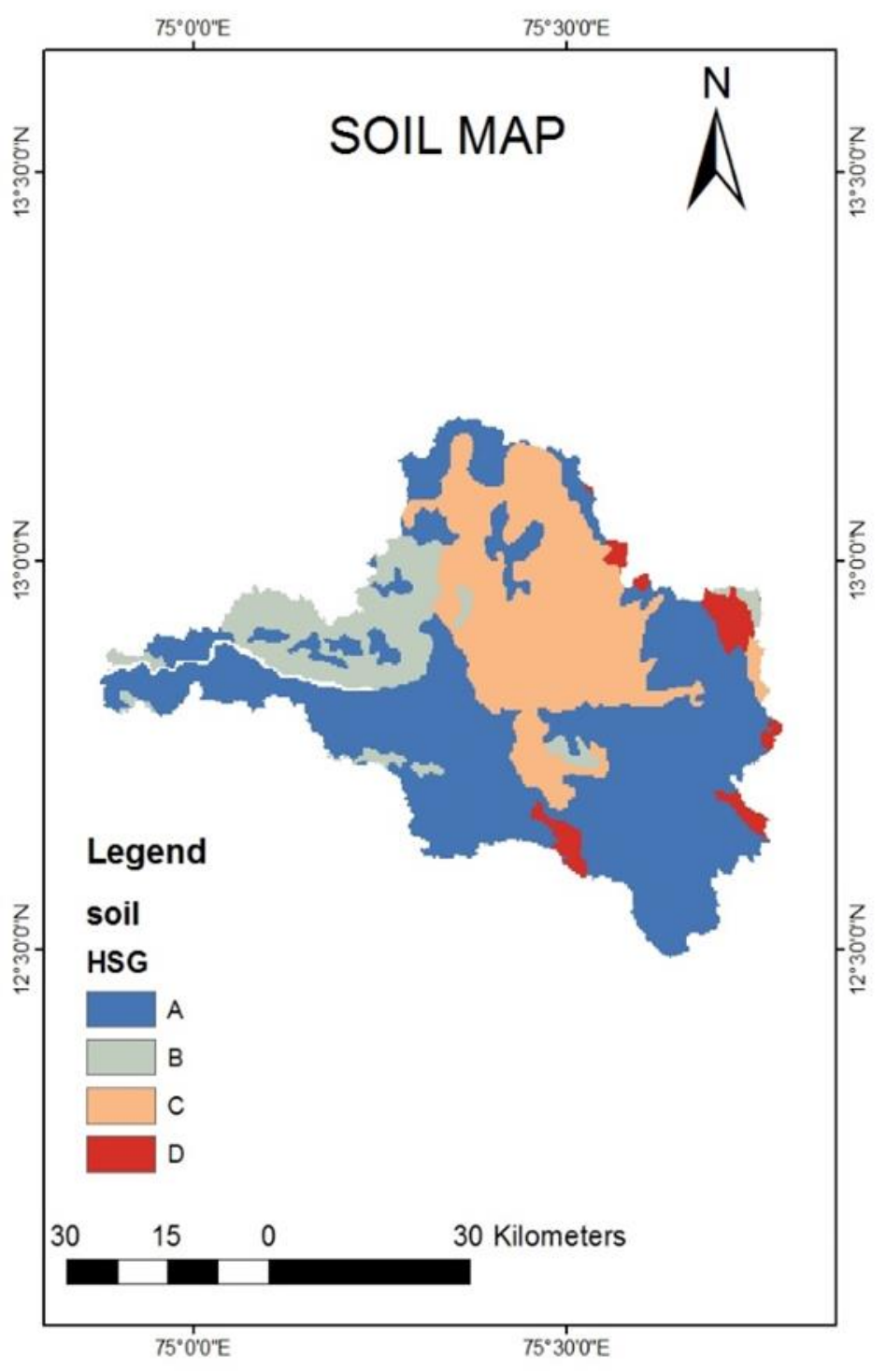

Figure 3. Soil Map of Netravathi basin 


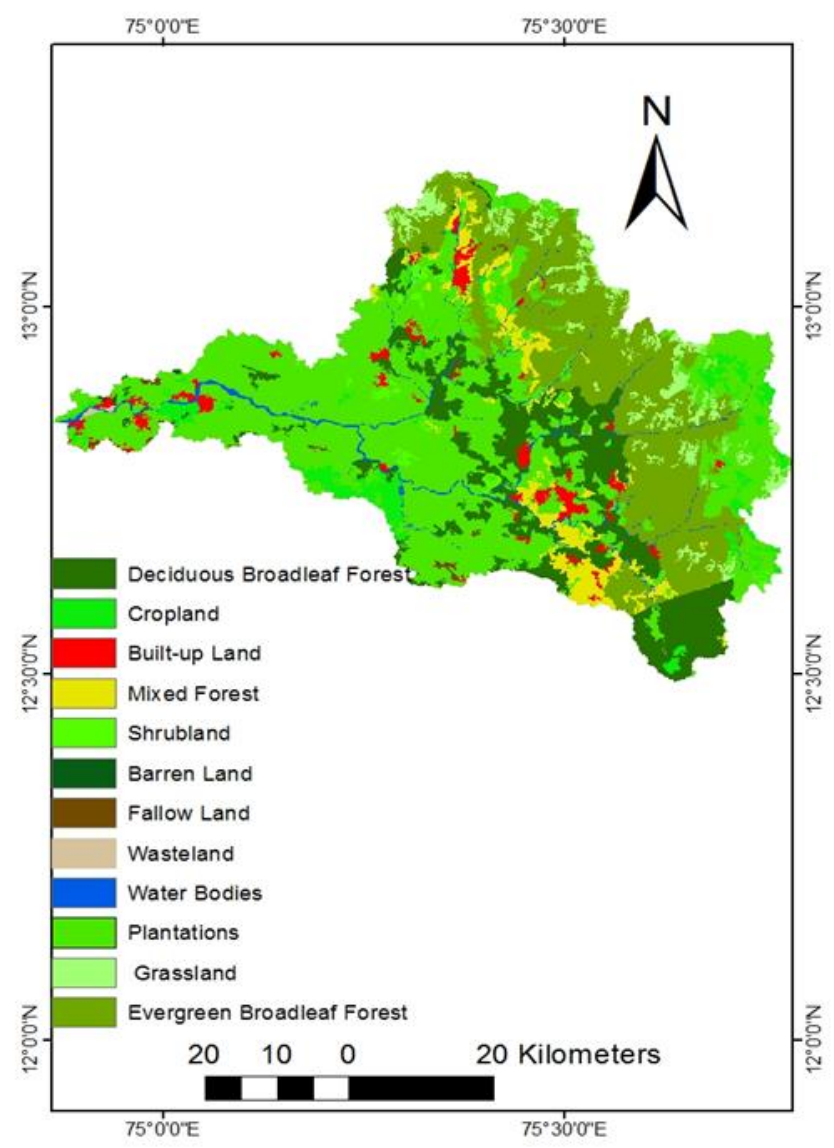

Figure 4. The LU/LC map of Netravathi basin 


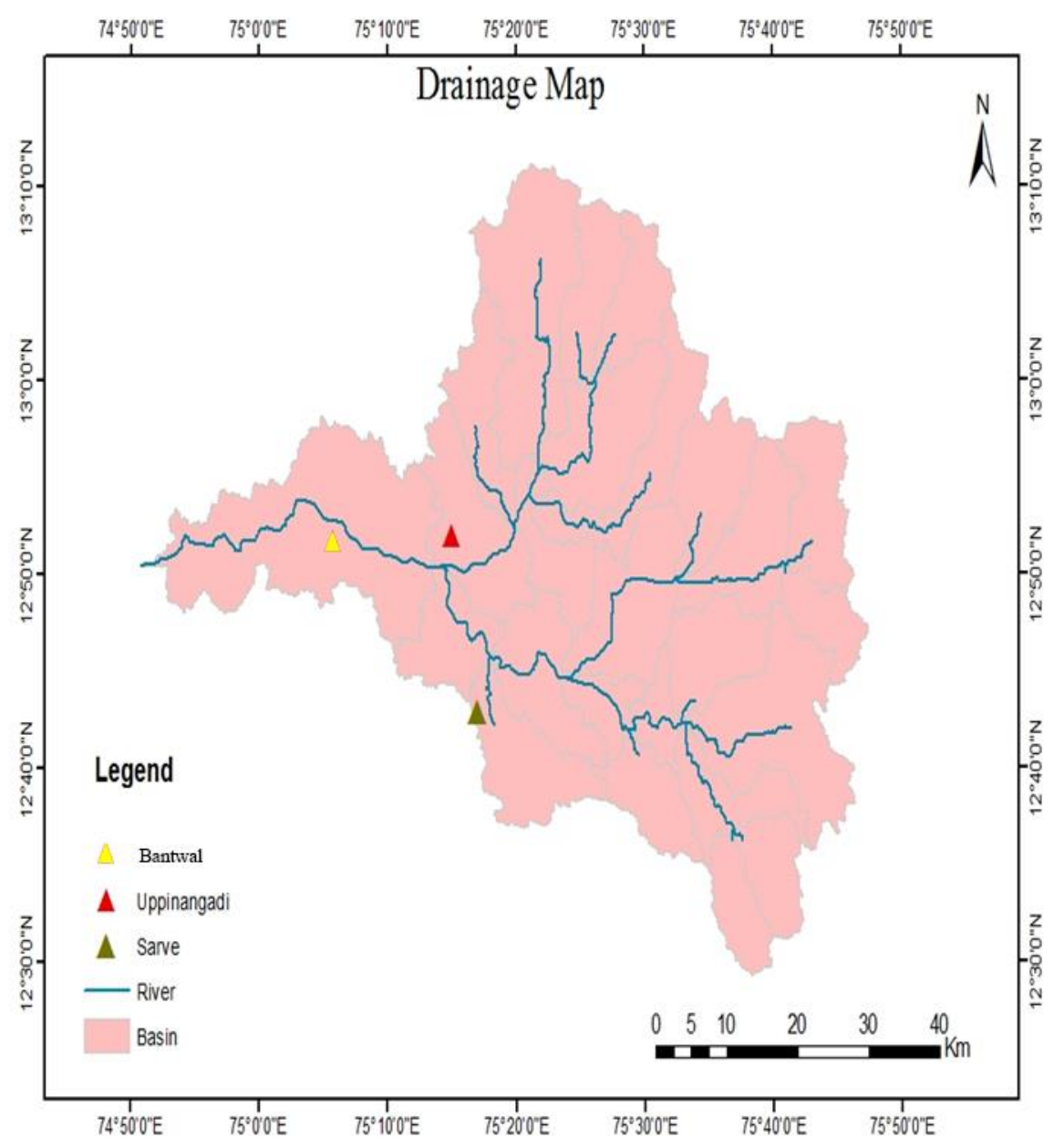

Fig. 5. Drainage map of Netravathi river with gauging stations 

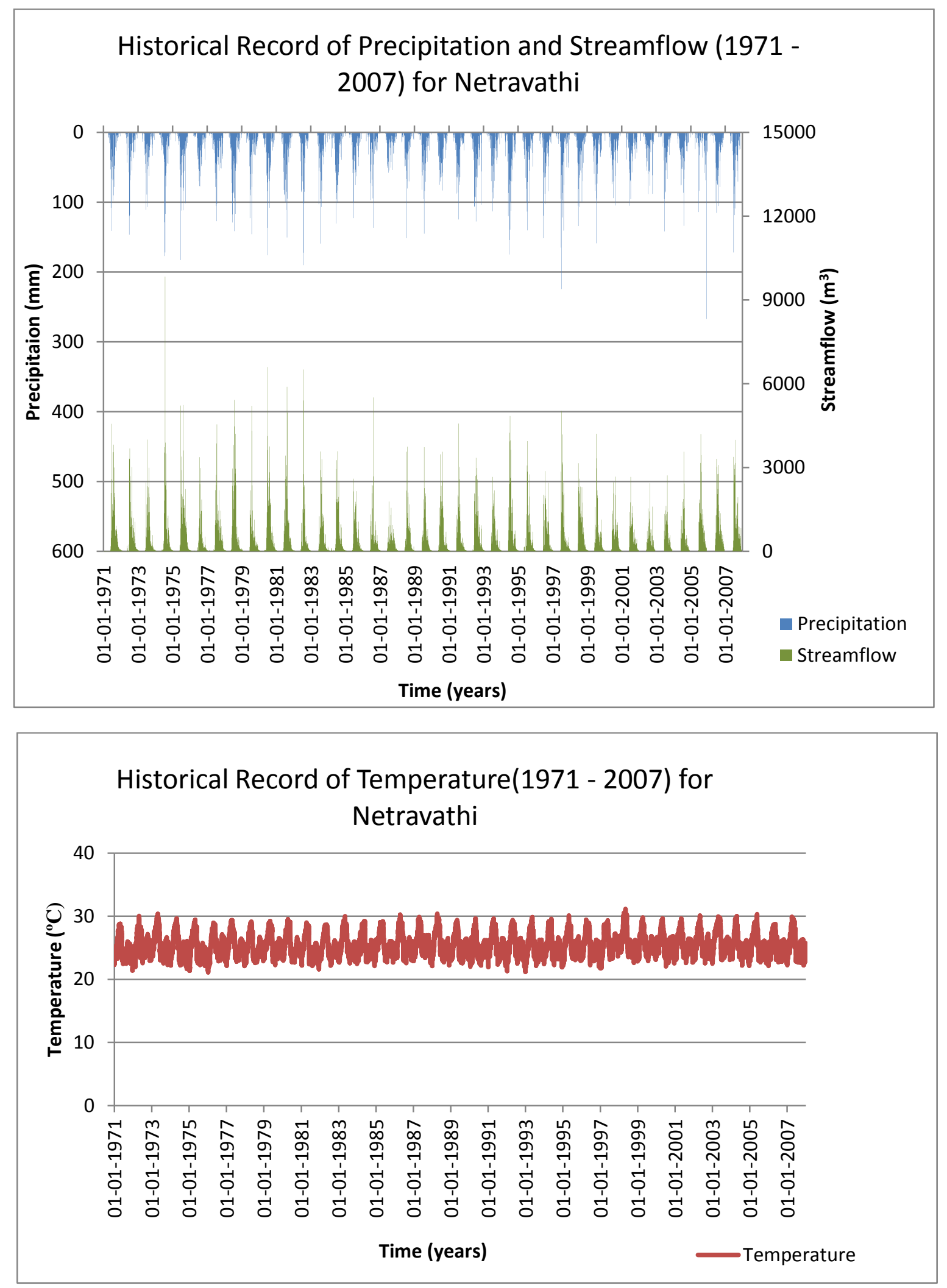

Figure 6. Historical record of precipitation, streamflow and temperature for Netravathi basin 


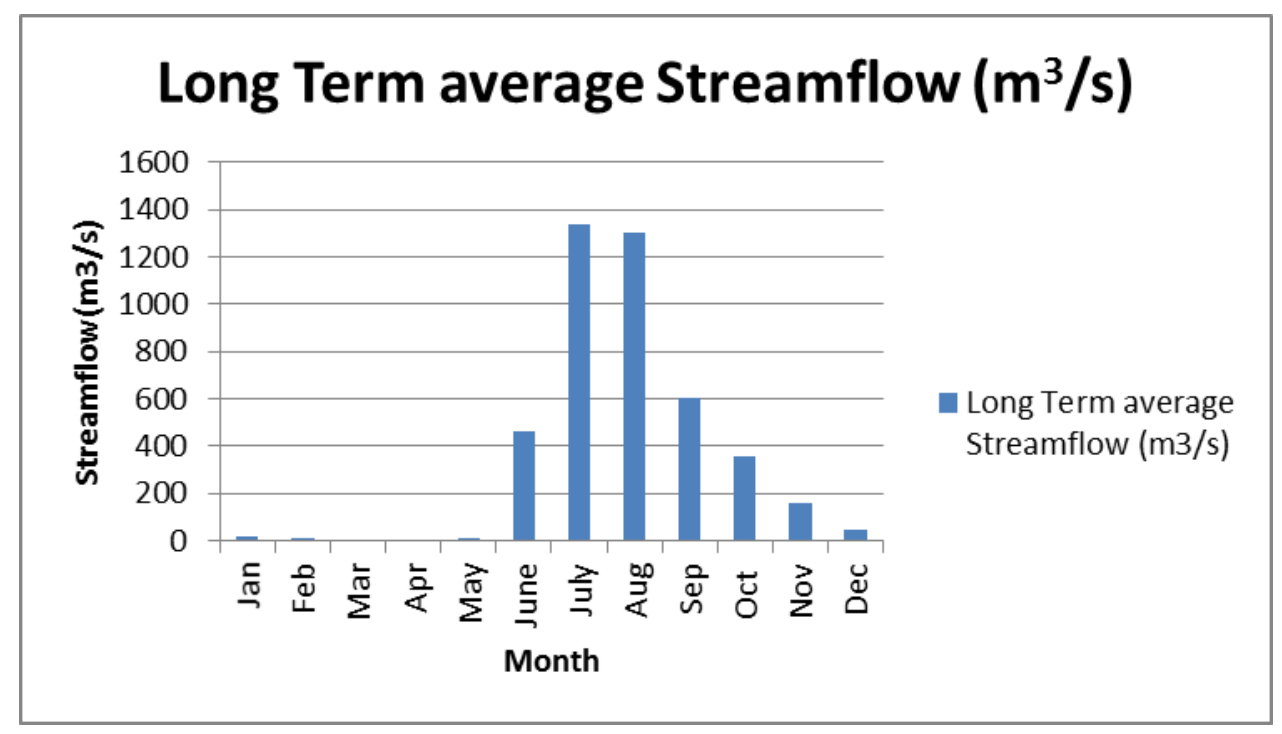

Figure 7. Long term monthly average streamflow at Bantwal station (1971-2007) 


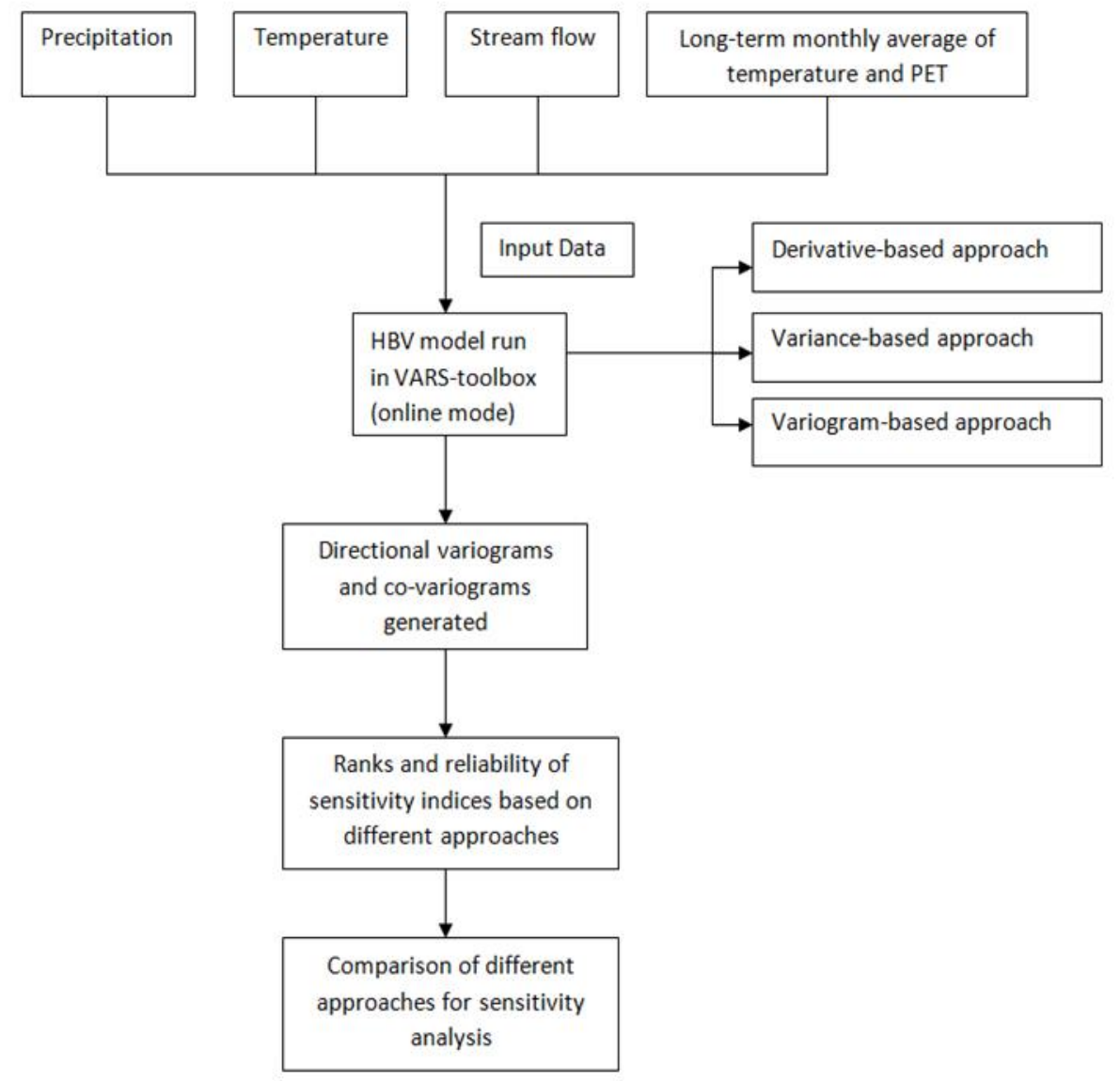

Fig. 8. Methodology of the present simulation 


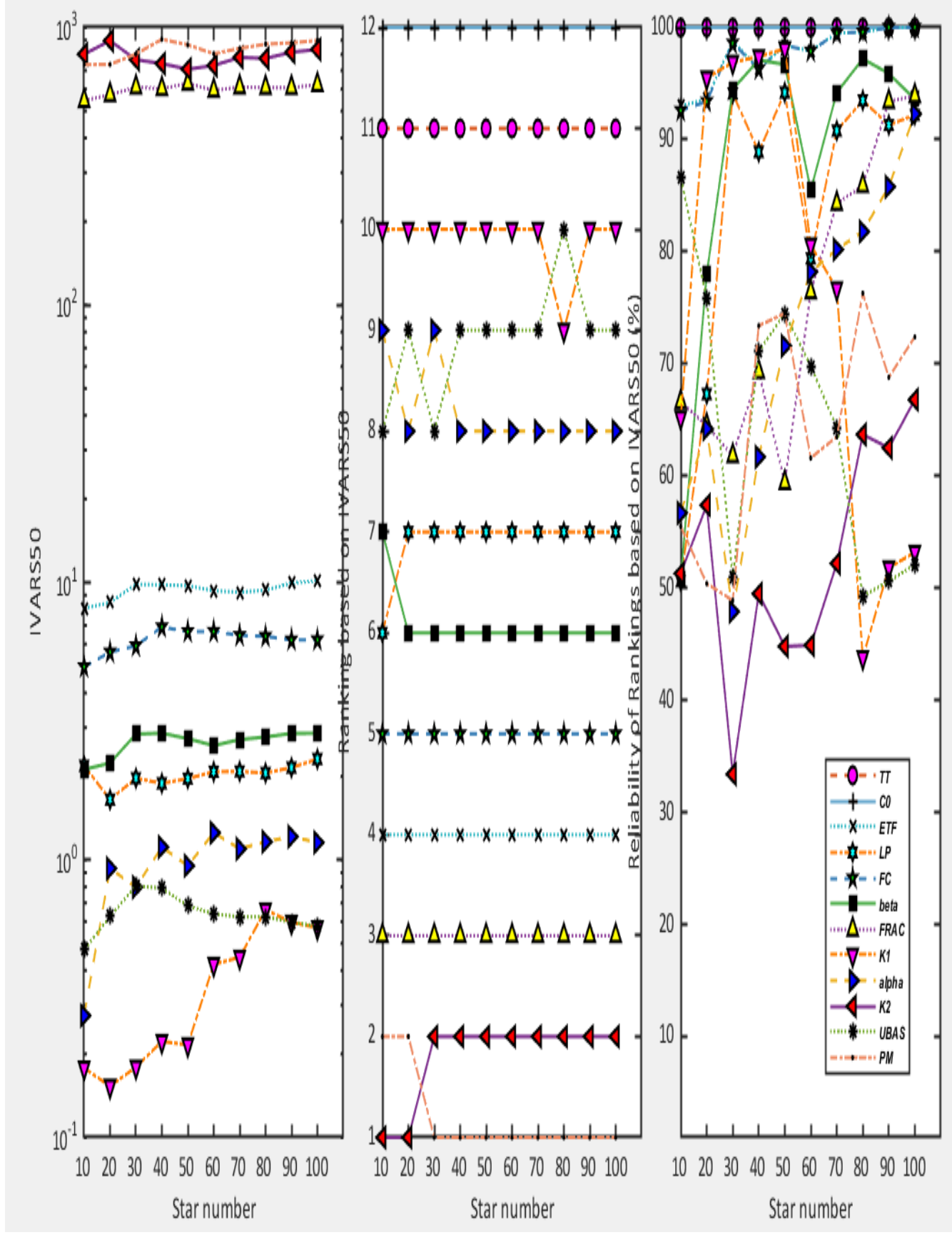

Fig. 9. Evolution and convergence of sensitivity indices after GSA execution for Nethravathi basin 

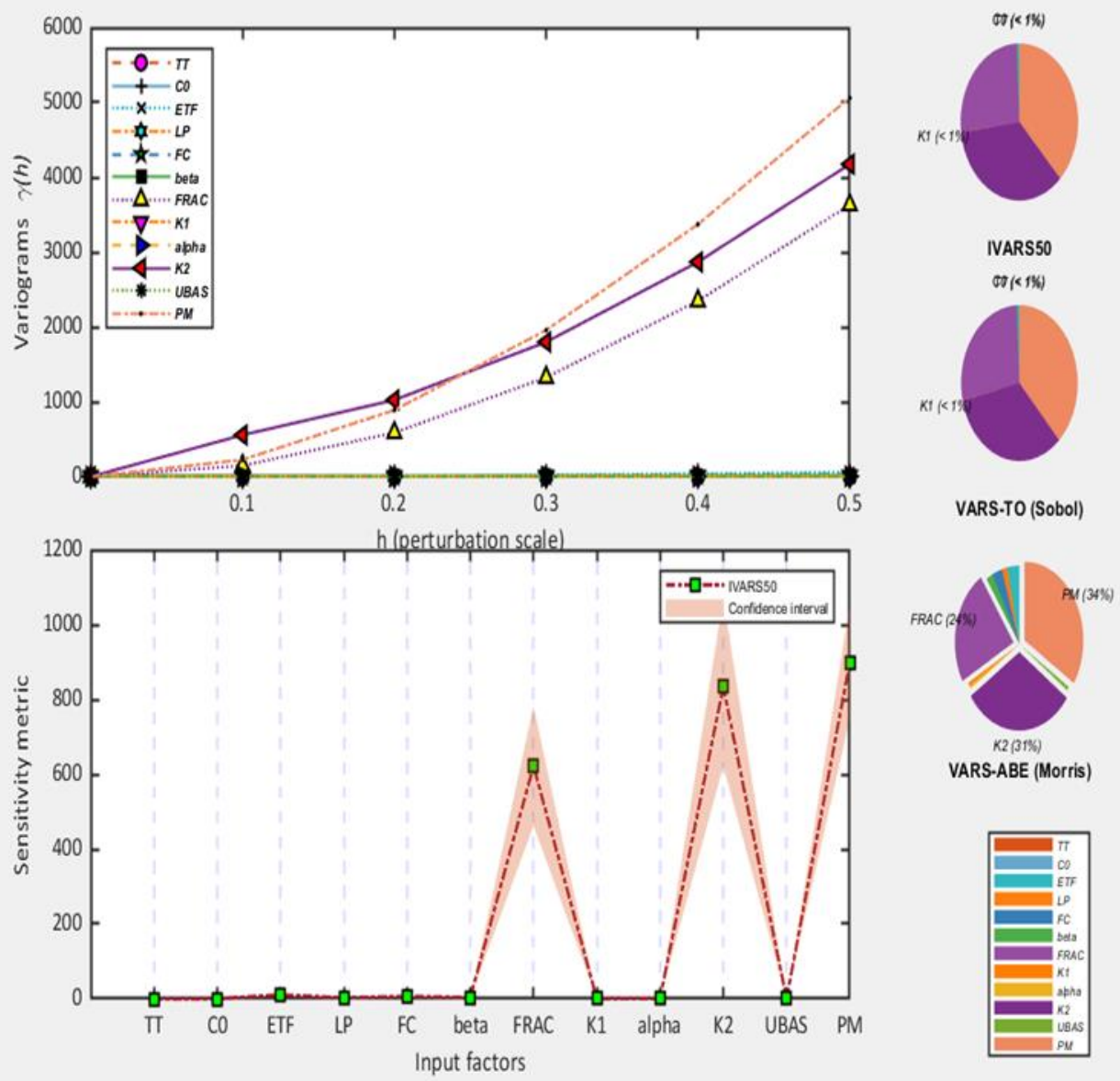

Figure 10. Detailed GSA results - directional variogram across the range of perturbation scales for Netravati basin 


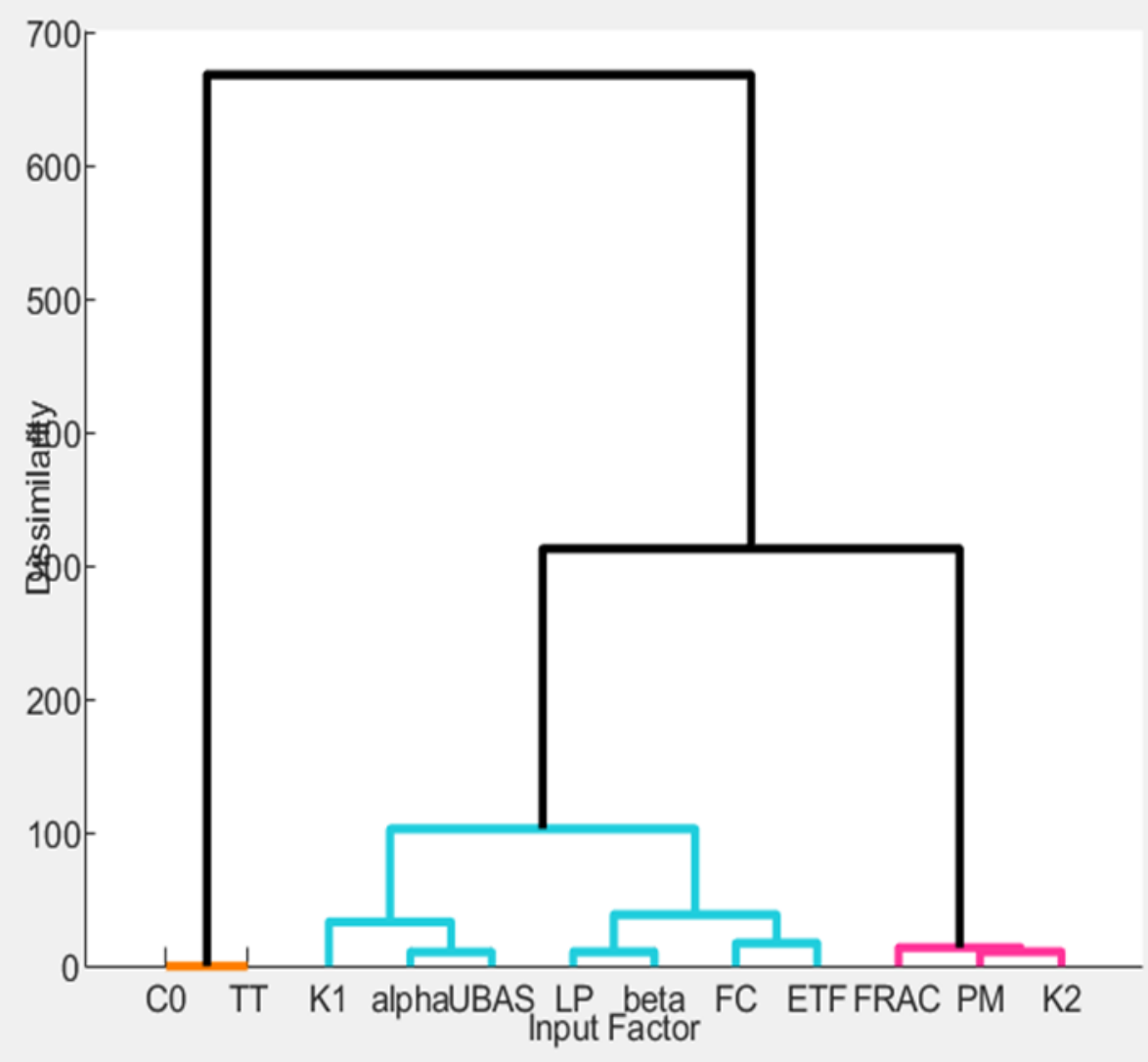

Figure 11. Dendrogram for factor grouping 